\title{
Erratum to: Genetic polymorphisms in phase I and phase II enzymes and breast cancer risk associated with menopausal hormone therapy in postmenopausal women
}

The MARIE-GENICA Consortium on Genetic Susceptibility for Menopausal Hormone Therapy Related Breast Cancer Risk

Published online: 19 September 2009

(C) Springer Science+Business Media, LLC. 2009

Erratum to: Breast Cancer Res Treat

DOI 10.1007/s10549-009-0407-0

Unfortunately Corresponding Author's (Jenny ChangClaude) affiliation and e-mail have been missed out in the original publication and they are given below.

The online version of the original article can be found under doi:10.1007/s10549-009-0407-0.

Division of Cancer Epidemiology, Unit of Genetic

Epidemiology, German Cancer Research Center (DKFZ),

Im Neuenheimer Feld 280, 69120 Heidelberg, Germany

e-mail: j.chang-claude@dkfz-heidelberg.de 